\title{
Extended-release Galantamine Hydrobromide
}

National Cancer Institute

\section{Source}

National Cancer Institute. Extended-release Galantamine Hydrobromide. NCI Thesaurus. Code C159888.

An extended-release (ER) formulation of the hydrobromide salt form of galantamine, a tertiary alkaloid obtained synthetically or naturally from the bulbs and flowers of Narcissus and several other genera of the Amaryllidaceae family, with anticholinesterase and neurocog nitive-enhancing activities. Upon administration, galantamine competitively and reversibly inhibits acetylcholinesterase, thereby increasing the concentration and enhancing the action of acetylcholine (Ach). In addition, galantamine is a lig and for nicotinic acetylcholine receptors, which may increase the presynaptic release of Ach and activate postsynaptic receptors. This agent may improve neurocog nitive function in mild and moderate Alzheimer's disease and may, through its Ach stimulating effect on nicotinic receptors, help quit smoking and reduce abstinence-induced cog nitive symptoms that promote smoking relapse. 